\title{
THE USER PARTICIPATION ON FACEBOOK PAGES OF THE THREE PORTUGUESE TV NEWS CHANNELS - RTP3, SIC NOTÍCIAS, AND TVI24
}

\author{
Sónia Ferreira ${ }^{1 *}$, Rui Rodrigues ${ }^{2}$ \\ ${ }^{1}$ Prof. Dr., Escola Superior de Educação, CI \& DETS, Instituto Politécnico de Viseu, PORTUGAL, \\ sonia.ferreira@esev.ipv.pt \\ ${ }^{2}$ Prof. Dr., Instituto Superior Miguel Torga, PORTUGAL, ruipcrodrigues@gmail.com \\ ${ }^{*}$ Corresponding Author
}

\begin{abstract}
In recent decades, the national and international media contexts, in particular television, media significantly changed. Although they were not created for the purpose, the role that social networks, in particular Facebook, have taken as a content diffusion platform is unquestionable. Nowadays, traditional media (radio, newspaper, television) use the Web's potential to distribute news content (Canelas, 2011). Currently, all TV news channels in Portugal have a website or a page on social networks. TV stations have increased communication channels with the public on digital platforms and study strategies that promote the participation and interaction with the news content (Cazajeira, 2015). The TV / Internet convergence will not only reach the content, but also the consumer, who becomes an interactive and participative audience. This reality imposes on journalism a continuous and updated news production system, dependent on a user being permanently connected to the Internet (Cazajeira, 2015). In fact, an ERC report (2015) confirms the relevance that social media has assumed in the publication and consumption of news. Social networks are recognised as one of the most important means for news media consultation, right after television, and the practice of sharing news is very common among consumers of online news in Portugal. Furthermore, when compared to other countries analysed by Reuters Institute (Newman, Levy, \& Nielsen, 2015), Portuguese consumers are those who make the most comments to online news, preferring social networks to news sites.

Considering the importance of new online platforms for journalism, this study aims to present a quantitative analysis of user participation on the Facebook pages of the three Portuguese TV news channels, specifically RTP3, SIC Notícias and TVI24, between 8 and 14 February 2016. To track this participation, the following parameters were used: the "like" button as a way to study the demonstration of publication interest; "sharing" of a particular element, be it a photo, a video or a text, on their own Timeline, the Timeline of a friend or by private message. This monitoring is important to understand the dissemination of news content; and the comments area. The number of comments will help understand the dynamics and the discussion that the publication has on the public.
\end{abstract}

The results of 1063 posts indicate that of the analysed parameters - "Like", "Comment", and "Share" - the one with the greatest power of participation among the users of the pages of the three Portuguese TV news channels is the "Like" system, followed by "Share" and then "Comment". Analysing the thematic that create the most user participation with "Likes" and "Comments" parameters are "Science and Technology". "Education" and "Humorous/Satirical/Unusual Finally, the publications available end of the night (10pm-1am) has better participation rates.

Keywords: TV News Channels, Facebook, User Participation 


\section{INTRODUCTION}

With the advent of the Internet and subsequently the massification of web 2.0 and social network sites (SNS), the content consumption has changed and thereby, consumption habits have also suffered changes. The concept of convergence culture, introduced by Jenkins (2006), explains the existing changes in the content consumption carried out by individuals. As regards the regulator for the media in Portugal $(\mathrm{ERC})^{1}$, the convergence and integration of traditional media with digital media (and vice versa), allowed consumption and participation with contents from different and complementary ways (ERC, 2015). Much has been speculated about the replacement of traditional media in digital media. Once again, Jenkins (2006) states this will not be a replacement, but an integration, coexisting with services, such as SNS's. The author also establishes the concept of convergence between content producers and users, indicating that there is a technological and cultural convergence between them. It is technological because the content circulates in different communication platforms, and it is cultural because the audience has the ability to use SNS's to connect in many ways and actively shaping the content. These changes publicly challenge the interests of the mass media producers (Jenkins, 2006), including the TV news channels.

Today, these channels have an increasingly presence in SNS's, specifically Facebook, the second most viewed website in Portugal (Alexa, 2016). These channels see Facebook as an excellent service to publish news and redirect the users to their websites (Castillo, El-Haddad, Pfeffer, \& Stempeck, 2014; Hille \& Bakker, 2014; Oeldorf-Hirsch \& Sundar, 2015). From the point of view of those who consume, online news tend to generate comments and promote sharing among users. This participation influences the users that will consume the content shared by others. Applying Jenkins assumptions, these services become an excellent example of user participation in the information content, where users abandon a position of receptors news information, and play a role of creators and disseminators of content - prosumers (Jenkins, 2006). Currently, SNS's are distribution platforms of news content, where the dynamics of publications, as well as the participation between users and content, are reshaping the way that news content are consumed (Hermida, Fletcher, Korell, \& Logan, 2012). In this context, the main purpose of this paper is to analyze the participation of users on the Facebook pages of the three main news channels of Portuguese TV: RTP3, SIC Notícias, and TVI24. For this analysis are used the parameters available in each publication of Facebook: "Like", "Comment", and "Share". The aim is to make considerations on how users interact with the content available on the Facebook pages of TV news channels, taking into account both the publications parameters, and the time of the day which there is greater participation of users.

\section{LITERATUTE REVIEW}

In recent years, the overall picture of media has been suffering huge changes. The technological evolution has resulted in the proliferation of new content delivery platforms. The content got new means of expression and access by consumers, which gradually abandoned the unique role of receptors (Bruns, Highfield, \& Lind, 2012; Hermida et al., 2012; Lamas, 2013). As Brecht predicted, the new audiences call for new content and new ways of participation. López (2007) said that new technologies open other ways for the participation of users, and the media feel the need to approach the users on these platforms, in order to take effect and be useful. These new ways of participation, and transmedia context, did not only revolutionized the content and the supports in which these contents can be displayed, also influenced the newsrooms and the way how journalists research information (Jacobson, 2013). For example, the content available on the Internet and SNS's are already an important source of information to journalists, and therefore changed some habits in obtaining this information (Dias, 2010). The relationship between the news organizations and their audience has today many ways to consume and share content. Whereas previously, this relationship was mainly made by mail or phone, nowadays such communication and feedback are done by e-mail. This interaction can also be made in the several digital platforms provided by news organizations, as well as in the comments present on forums or SNS's of these organizations (Dias, 2010). Now, there are other ways to interact and participate with the content, and there are also many participants who wish to intervene. The use of SNS's by the TV news channels, specifically the Facebook, has allowed users to send content that appears sometimes on TV news of the respective channels. An example of this intervention is related with the use of amateur videos. In breaking news, the journalists does not arrive on time to the scene, and thanks to the content provided by users, these journalists can portray this story more quickly.

Currently, consumers are not only looking for a source of news. They use all your entire network for content consumption (Aitamurto \& Lewis, 2013). SNS's, including Facebook, have also contributed to the change of media reality. The Facebook has features that differentiate it from other services, facilitating the publication,

\footnotetext{
${ }^{1}$ It is an autonomous institution that has the function of supervising and regulate the media in Portugal.
} 
discussion and sharing of content (Sousa, 2014). In these services, the users had a sense of control the information, making them an important source for their network (Oeldorf-Hirsch \& Sundar, 2015). Bruns et al. (2012) call these users as "produsers", since they are not users who only consume content and are not content producers, but are users who share content provided by others. These participation and content sharing allowed by Facebook, it becomes even more attractive for the new generations, as suggested by Reuters Institute and the ERC reports (ERC, 2015; Newman et al., 2015). The new generations are more predisposed to consume news in other way, where the TV is not the only media that they focus, sharing their attention with other tasks or devices. Thanks to the ability of multitasking, these are generations that will become new players in a new way of information consumption. Thus, the consumption of news is changing quickly, and audiences are increasingly divided. Given this paradigm, the SNS's, specifically Facebook, have the ability to increase the number of news consumers, since most of them are always online. Moreover, according to a study carried out by Baresch, Knight, Harp, and Yaschur (2011), 49\% of Facebook users share information through links, and news are the most shared content. The investment in these services becomes crucial (Mota \& Barbosa, 2014), and Facebook is a SNS that deserves the attention of news organizations.

\subsection{Online news in Portuguese context}

With traditional media, the audience only receive the content distributed by news organizations (Hermida et al., 2012). Nowadays, some part of audience does not passively consume content provided by these organizations. About one third of users have already used social media to comment news content, to post a link to a news story, or even created their own news (Purcell, Rainie, Mitchell, Rosenstiel, \& Olmstead, 2010). In this context, many news organizations, including TV news channels, use SNS's as an important source to establish a relationship with their audience. Proof of this are the resources that organizations already spend on SNS, in order to maintain audience updated (Ju, Jeong, \& Chyi, 2014). In the case of Portugal, there are also some differences with respect to the time of the day that the audience consults news, regardless of the media used. According to the Public and Consumption Media report, the consumption of these news are greater in the early morning and between the beginning and the end of the night (ERC, 2015, p. 28).

In terms of SNS's, 66\% of respondents identified them as one of its main news resources (ERC, 2015). These emerge as the second most important source for access to news content after the television (ERC, 2015). In fact, television is still the main news source. However, more than a half of the participants also use the websites, or applications of news organizations, to news access. Using online sources for news consultation, SIC Notícias and TVI24 are the news channels that most participants use to access news, respectively $21 \%$ and $15 \%$ (ERC, 2015). It is important to emphasize that the Portuguese case is different from other countries, where TV channels are also preferred sources in news online consultation. In Portugal, although users are interested in news, when compared with other countries, the users consume less news in online context (Newman et al., 2015). According to the same report (ERC, 2015), SNS's emerge as the second most important source of news, and television programs are the first one (93\%). The same study recognizes Facebook as the SNS more used for news updates and analysis of texts. This report highlight the importance of Facebook in Portugal, since this SNS is the second most visited page in Portugal (Alexa, 2016). It is also important to refer Twitter, a SNS very popular in journalists, but with little relevance in the news update by the news organizations. Regarding the online participation, share news through SNS's is a very common practice among users. More than half (55\%) share news content weekly. According to data from ERC, Portugal is the country where this practice is more regular (ERC, 2015). The same report indicates that when compared with other countries, Portuguese consumers are those who publish more comments. However, they prefer make these comments on social networks than on the official webpages of TV news channels, respectively $39 \%$ and $19 \%$ (ERC, 2015). This situation occurs in all countries analysed, and demonstrates the importance that SNS's has in the context of news consumption.

Finally, it is also known that the preferences of users may be different depending on their interests. According to the Public and Media Consumption report, users are more interested in national news (92\%), and preferred thematic such as: "Sports" (37\%) and "Health and Education" (40\%) (ERC, 2015). The audience and the profile of viewers can influence the alignment of the contents, as is the case of social media (Jacobson, 2013).

\section{RESEARCH HYPOTHESIS}

After the literature review performed, this article intends to study the user participation on the Facebook 
pages of TV news channels. To this end, the authors selected the three news channels of Portuguese TV most used for news consumption: RTP3, SIC Notícias, and TVI24 (ERC, 2015).

The research developed and reported in this paper is based on three research hypotheses:

H1: Considering the main user participation parameters of the Facebook, "like", "comment" and "share", in three TV news channels of Portuguese TV, "like" is the most used parameter.

To understand the participation between the audience and Facebook pages, we can use the parameters that Facebook provides in each publication: "Like", "Comment" and "Share". This hypothesis aims to verify which of these parameters is the most used by users on the three Facebook pages of RTP3, SIC Notícias, and TVI24. This hypothesis has also the purpose of showing that users are not only receptors of information, corroborating some studies that indicate that the SNS's, such as Facebook, are tools that allows users to interact with the news anytime, anywhere (Baresch et al., 2011; ERC, 2015; Newman et al., 2015; Purcell et al., 2010).

H2: In terms of thematic, the users' participation on Facebook pages of the three news channels of Portuguese TV is higher in "National News", and news about "Health", "Education" and "Sport".

According to the ERC report (2015), users are more interested in national news (92\%), and about the thematic "Sports" (37\%) and "Health and Education" (40\%). From the parameters "Like", "Comment", and "Share", this hypothesis intends to verify whether this interest is higher in these thematic or in any other. In order to classify the Facebook publications, the authors used thematic categorizations referred on reports of the ERC and the Reuters Institute (ERC, 2015; Newman et al., 2015). The authors also taking into account the division of the news in "National News" and "International News" (Brandão, 2009; Lopes, 1999).

H3: Considering the time of the day that occurs publications on the Facebook pages of RTP3, SIC Notícias, and TVI24, the participation is higher in the early morning and night (beginning and end of the night).

The third hypothesis is intended to realize if the participation of users changes throughout the day. Once again, the parameters that Facebook provides in each publication: "like, "share", and "comment" will be used. Therefore, it is intended to verify if the user's participation is higher in times of the day that most users consult news. According the ERC report (ERC, 2015), the news consumption is higher in the early morning and between the beginning and the end of the night, and users access to SNS's several times a day (ERC, 2015; Newman et al., 2015; Oeldorf-Hirsch \& Sundar, 2015), which makes their online presence be permanent.

\section{METHOD}

This paper studies how users participate on the Facebook pages of the three news channels of Portuguese TV (RTP3 ${ }^{2}$, SIC Notícias ${ }^{3}$, and TVI24 ${ }^{4}$ ). To this end, the authors analysed, quantitatively, the user participation using the following parameters: "like", "share", and "comment". These data were collected on Facebook pages of RTP3, SIC Notícias, and TVI24, between the $8^{\text {th }}$ and $14^{\text {th }}$ of February (one week).

Statistical analysis was performed using IBM SPSS 23.0 - Statistical Package for Social Sciences, and the parameters analysis was:

i. Time of the Day: It concerns the time of the day in which a publication is available on the Facebook pages of the three TV news channels. The authors chose to follow the time of the day mentioned on ERC report (ERC, 2015): "in the morning" (7am-10am), "late morning" (10am-1pm), "early afternoon" $(1 \mathrm{pm}-4 \mathrm{pm})$, "afternoon" (4pm-7pm), "in the early night"(7pm-10pm), and "the end of the night" (10pm$1 \mathrm{am})$;

ii. National or International News: Division of the news in "National News" and "International News", according to Lopes (1999) and Brandão (2009) categorization;

iii. Thematic: It concerns to the main thematic present in each Facebook publication. The same news may have sometimes more than one thematic identified. In these cases, it is the main thematic that will be categorized. The thematic are based on the "Reuters Institute Digital News Report", 2015, but the

\footnotetext{
${ }^{2}$ http://www.rtp.pt/play/direto/rtp3

3 http://sicnoticias.sapo.pt/

4 http://www.tvi24.iol.pt/
} 
authors added the categories "Opinion" and "Other". The authors also opted to separate the category "Society" of "Entertainment/Celebrities", and rename the category for "Country/Society". This category represents all the local/region/town news. Thus, the categories under consideration are: "Country/Society", "Economy", "Health", "Education", "Financial/Business", "Entertainment/Celebrities", "Art and Culture", "Politics", "Science and Technology", "Sport", "Humorous/Satirical/Unusual", "Opinion", and "Other";

iv. "Like" button: Demonstration of interest publication without having to write a comment;

v. "Comment" area: The number of comments will help understand the participation and the discussion that the publication has on the users;

vi. "Share" button: The dissemination of a publication on its own timeline or on a friend's timeline.

\section{RESULTS \& DISCUSSION}

During the period from February 8 to February 14 of 2016, the three TV news channels published on their Facebook pages 1063 posts - 188 made by RTP3, 424 by SIC Notícias, and 451 by TVI24. It is also important to refer that the Facebook pages of RTP3 has 254.554 likes, SIC Notícias has 876.856 likes and TVI24 has 486.843. The data collected of "likes" was made on February 5, 2016.

\section{1 "Likes", "Comments" and "Shares" in the three TV news channels}

According to the monitoring of participation on the Facebook pages of the three TV news channels, "like" it is the parameter most used by users. As shown in Table 1, RTP3 have made 188 publications that generated a total of 15.260 "Likes", 2.027 "Comments", and 2.677 "Shares". On the Facebook page of SIC Notícias were published 425 posts that caused 164.376 "Likes", 12.511 "Comments", and 28.415 "Shares". Finally, in the TVI24 Facebook page, were published 451 posts that promote 120.516 "Likes", 9.300 "Comments" and 22.881 "Shares".

Table 1 - "Likes", "Comments", and "Shares" on Facebook Pages of RTP3, SIC Notícias, and TVI24

\begin{tabular}{|l|c|c|c|c|c|c|}
\hline \multirow{2}{*}{ TV news channel } & \multicolumn{3}{|c|}{ Parameters } \\
\cline { 2 - 8 } & \multicolumn{2}{|c|}{ Likes } & \multicolumn{2}{c|}{ Comments } & \multicolumn{3}{c|}{ Shares } \\
\cline { 2 - 8 } & $\mathrm{M}$ & $f$ & $\mathrm{M}$ & $f$ & & $\mathrm{M}$ \\
\hline RTP3 & 81.2 & 15.260 & 10.8 & 2.027 & 14.2 & 2.677 \\
\hline SIC Notícias & 387.7 & 164.376 & 29.5 & 12.511 & 67.0 & 28.415 \\
\hline TVI24 & 302.8 & 120.516 & 23.4 & 9.300 & 57.5 & 22.881 \\
\hline
\end{tabular}

RTP3: N=188; SIC Notícias: N=425; TVI24: N=451

$M=$ Mean; $f=$ frequency

It is also important to note that the TVI24 has more publications during the period under review, compared with the other two TV news channels (SIC Notícias and RTP3). However, in terms of mean values, the publications made by SIC Notícias had a higher participation in the three parameters under consideration: "Likes" (M=387.7), "Comments" $(M=29.5)$, and "Shares" $(M=67.0)$. According to ERC (2015), the brand SIC Notícias emerges as the most used source to consume online news (21\%). Moreover, SIC Notícias is the TV news channel that have more "Likes" on their Facebook page (876.856), and consequently has a higher number of potential users to interact with their news content.

This results appears to be related to the results presented in the ERC report (ERC, 2015) and the hypothesis formulated in this research $(\mathrm{H} 1)$.

\subsection{Users participation by thematic}

\subsubsection{Thematic: Country/Society, Economy, Health, Education, Financial/Business, Entertainment/Celebrities, Art and Culture, Politic, Science and Technology, Sport, Humorous/satirical/unusual, Opinion, and Other:}

According to the data collected, in terms of mean values and in descending order, the thematic that generated more "Likes" were: "Humorous/Satirical/Unusual" ( $M=956.9)$, "Science and Technology" $(\mathrm{M}=542.6)$, and "Entertainment/Celebrities" $(M=432.7)$. Concerning of "Comments" parameter, the publications that have generated more participation were: "Education" $(M=92.0)$, "Economy" $(M=51.8)$, and 
"Politic" ( $M=44.9)$. Finally, the most shared thematic were: "Humorous/Satirical/Unusual" $(M=189.6)$, "Education" ( $M=177.7)$, and "Science and Technology" $(M=100.6)$.

Table 3 - User participation by thematic - Country/Society, Economy, Health, Education, Financial/Business, Entertainment/Celebrities, Art and Culture, Politic, Science and Technology, Sport, Humorous/satirical/unusual, Opinion, and Other

\begin{tabular}{|c|c|c|c|c|c|c|}
\hline \multirow{3}{*}{ Thematic } & \multicolumn{6}{|c|}{ Parameters } \\
\hline & \multicolumn{2}{|c|}{ Likes } & \multicolumn{2}{|c|}{ Comments } & \multicolumn{2}{|c|}{ Shares } \\
\hline & $\mathrm{M}$ & $f$ & $\mathrm{M}$ & $f$ & $\mathrm{M}$ & $f$ \\
\hline Country/Society & 275.9 & 114.232 & 15.6 & 6.472 & 58.3 & 24.151 \\
\hline Economy & 228.7 & 17.842 & 51.8 & 4.039 & 67.1 & 5.238 \\
\hline Health & 157.5 & 5.199 & 12.1 & 398 & 38.4 & 1.267 \\
\hline Education & 305.9 & 2.753 & 92.0 & 828 & 177.7 & 1.599 \\
\hline Financial/Business & 111.1 & 2.999 & 14.8 & 399 & 15.4 & 416 \\
\hline Entertainment/Celebrities & 432.7 & 21.634 & 11.1 & 555 & 30.6 & 1.532 \\
\hline Art and Culture & 228.9 & 12.132 & 6.2 & 328 & 28.1 & 1.488 \\
\hline Politic & 209.8 & 23.705 & 44.9 & 5.072 & 39.5 & 4.466 \\
\hline Science and Technology & 542.6 & 20.618 & 13.4 & 510 & 100.6 & 3.824 \\
\hline Sport & 429.5 & 45.097 & 31.9 & 3.352 & 33.7 & 3.536 \\
\hline Humorous/Satirical/Unusual & 956.9 & 22.967 & 42.3 & 1.014 & 189.6 & 4.550 \\
\hline Opinion & 172.9 & 4.323 & 19.8 & 495 & 37.2 & 929 \\
\hline Other & 162.2 & 6.651 & 9.2 & 376 & 23.8 & 977 \\
\hline
\end{tabular}

"Country/Society": N= 414 posts; "Economy": N=78 posts; "Health": N=33 posts; "Education": N=9 posts;

"Financial/Business": N=27 posts; "Entertainment/Celebrities": N=50 posts; "Art and Culture": N=53 posts;

'Politic": N=113 posts; "Science and Technology": N=38 posts; "Sport": N=105 posts;

"Humorous/Satirical/Unusual”: N=24 posts; "Opinion": N=25 posts; "Other": N=41 posts

२TP3: N=188; SIC Notícias: N=425; TVI 24: N=451

И: Mean; $f=$ frequency

Overall, the thematic that have more publications were "Country/Society" $(\mathrm{N}=414)$, "Politic" $(\mathrm{N}=113)$, and "Sport" $(\mathrm{N}=105)$. However, in terms of mean values, these were not the thematic that generate more participation by users, as can be seen in Table 3. According to the report conducted by ERC (2015), the thematic that consumers show more interest, regardless of the media used, are: "Sports", "Health" and "Education". However, with the exception of "Education", the results shown that exist other topics where there is greater participation by users, such as "Humorous/Satirical/Unusual" and "Science and Technology". This difference may be related to the increasingly audiences division (Baresch et al., 2011; Ju et al., 2014; Oeldorf-Hirsch \& Sundar, 2015; Purcell et al., 2010), and therefore, different audiences also use different media for news consumption.

\subsubsection{National News vs International News}

Considering the "National News" and "International News" posted on the Facebook pages of the three TV news channels (RTP3, SIC Notícias, TVI24) the data collected indicate that users preferred "National News".

Overall, the total number of publications is superior in "National News" $(\mathrm{N}=636)$ than in "International News" $(\mathrm{N}=374)$. As can be seen in Table 3, the mean values of the parameter "Like" are similar ("National News" = 303.0 and "International News" = 287.1). However, the mean values of "Comments" is twice as high in the "National News" than in "International News", respectively $M=30.0$ and $M=12.4$. Finally, the mean values of "Shares" is also superior in "National News", when compared to "International News" (M=59.3 and M=43.4). 
Table 3 - User participation in National News and International News

\begin{tabular}{|l|l|c|c|c|}
\hline \multicolumn{2}{|l|}{} & \multicolumn{3}{c|}{ Parameters } \\
\hline \multicolumn{2}{|l|}{ National vs International } & Likes & Comments & Shares \\
\hline National news & $f$ & 192.765 & 19.182 & 37.720 \\
\cline { 2 - 5 } & $\mathrm{M}$ & 303.0 & 30.0 & 59,3 \\
\hline International news & $f$ & 107.387 & 4.656 & 16.253 \\
\cline { 2 - 5 } & $\mathrm{M}$ & 287,1 & 12,4 & 43,4 \\
\hline
\end{tabular}

National News: $\mathrm{N}=636$ posts; International News: $\mathrm{N}=374$ posts

M: Mean; $f$ : frequency

In fact, according to the ERC report (2015), almost all the respondents consider the "National News" as the most important news (92\%). The same result is similar for most of the countries analyzed by the study of the Reuters Institute (Newman et al., 2015).

Some of the results are consistent with the hypothesis proposed in this work $(\mathrm{H} 2)$, more specifically what concerns to the user participation in "National News". Nevertheless, in terms of thematic, the results did not corroborate with the hypothesis, and only "Education" had the expected results.

\subsection{Users participation by time of the day}

During the period of February 8 to February 14 2016, was published on the Facebook pages of the three TV news channels 1063 posts. The time of day when the TV news channels more news content publish are: "10am-1pm" (N=208) and "1pm-4pm" (N=173).

However, in terms of mean values, the results presented in Table 4 suggest that period "10pm-1am" is the moment of the day that generate more "likes" ( $M=373.2)$, and the periods of "10pm-1am" and "1pm- $4 \mathrm{pm}$ " are the times of the day that generate more "comments" $(M=29.4$ and $M=28.5)$. Finally, the publications made between "1pm-4pm" and "10am-1pm" generated more "Shares" ( $M=72.8$ and $M=59.3)$.

Table 4 - User participation by time of the day

\begin{tabular}{|l|c|c|c|c|c|c|}
\hline \multirow{2}{*}{ Time of the Day } & \multicolumn{5}{c|}{ Parameters } \\
& \multicolumn{2}{|c|}{ Like } & \multicolumn{2}{c|}{ Comment } & \multicolumn{2}{c|}{ Share } \\
\cline { 2 - 7 } & $\mathrm{M}$ & $f$ & $\mathrm{M}$ & $f$ & $\mathrm{M}$ & $f$ \\
\hline 7am-10am & 200.8 & 28.911 & 15.6 & 2.249 & 33.8 & 4.873 \\
\hline 10am-1pm & 278.7 & 57.979 & 25.6 & 5.333 & 59.3 & 12.335 \\
\hline 1pm-4pm & 338.5 & 58.562 & 28.5 & 4.888 & 72.8 & 12.601 \\
\hline 4pm-7pm & 334.6 & 51.193 & 23.8 & 3.648 & 59.0 & 9.021 \\
\hline 7pm-10pm & 300.3 & 49.245 & 21.7 & 3.562 & 46.3 & 7.598 \\
\hline 10pm-1am & 373.2 & 49.260 & 29.4 & 3.887 & 51.6 & 6.806 \\
\hline 1am-7am & 138.9 & 5.002 & 7.5 & 271 & 20.5 & 739 \\
\hline
\end{tabular}

"7am-10am": N=144; "10am-1pm": N=208; "1pm-4pm": N=173; "4pm-7pm": N=153;

"7pm-10pm": N=164; "10pm-1am": N=132; "1am-7am": N=36

M: Mean; $f=$ frequency

The differences of the user's participation recorded throughout the day on the Facebook pages of the three TV news channels of Portuguese TV, is more perceptible in the Fig. 1. 
User participation by time of the day

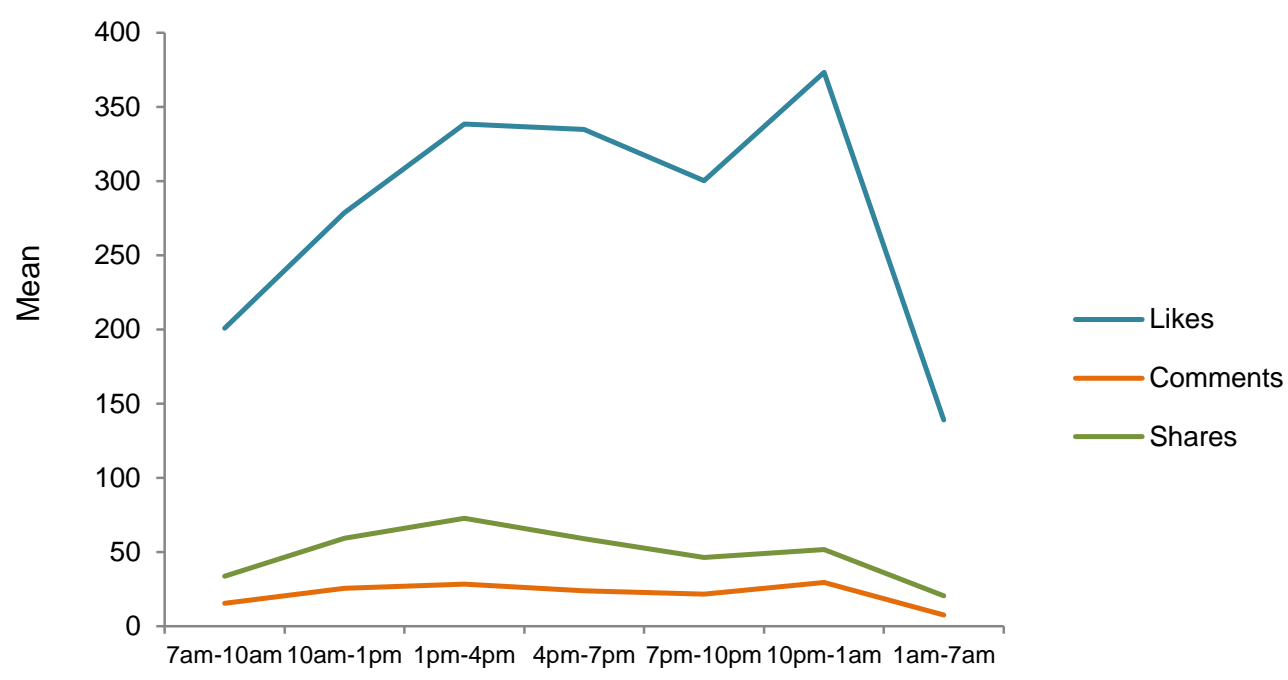

Time of the day

Fig. 1 Graphic representation of the mean values in terms of "Likes", "Comments" and "Shares on the Facebook pages of the three TV news channels of Portuguese TV

Overall, regardless the time of day, the users have greater participation in the form of "likes", and the time of day when it is most visible is in the range of $10 \mathrm{pm}-1 \mathrm{am}$ (end of the night). According to the ERC report (2015), the news consumption, in every media, is higher in the early morning and between the beginning and the end of the night. However, these results suggest that user participation is higher at the early afternoon $(1 \mathrm{pm}-4 \mathrm{pm})$ and at the end of the night $(10 \mathrm{pm}-1 \mathrm{am})$. In this context, the results suggest that may be exist a relation between the news consumption and user participation in the period of "10pm-1am", but in the remaining hours of the day, does not seem to be an obvious relation.

Some of the results are consistent with the hypothesis proposed in this work (H3), more specifically what concerns to the user's participation at the end of the night $(10 \mathrm{pm}-1 \mathrm{am})$. Nevertheless, at other times of the day, except from "7am-10am" and "1am-7am", user participation is constant, which may corroborate with some studies that indicate that, users' access to SNS's several times a day (ERC, 2015; Newman et al., 2015; Oeldorf-Hirsch \& Sundar, 2015).

\section{CONCLUSION \& FUTURE WORK}

Through this work it was possible to conclude some evidences about the user participation in the pages of the three Portuguese TV news channels - RTP3, SIC Notícias and TVI24. To understand the participation between the audience and Facebook pages of these three TV news channels, data were collected between 8 February and 14 February 2016.

The obtained results confirm that "Like" parameter is the most used by users on RTP3, SIC Notícias, and TVI24 Facebook pages'. Overall, the results suggest an active participation by the users. In fact, these results are corroborated by studies of Baresch et al. (2011), Hermida et al. (2012) and ERC (2015). These studies suggest that SNS's are platforms where the dynamics of publications, as well as the participation between users and news content, are reshaping the way that news content is consumed.

This research also showed that the thematic where there is greater participation by users are: "Education" "Humorous/Satirical/Unusual" and "Science and Technology". Although some studies refer that the preferred thematic of users are "Sport", "Health" and "Education" (ERC, 2015), only the last one was confirmed. This study also confirms that the users' participation on Facebook pages of three Portuguese TV news channels is higher in "National News".

Considering the time of the day when publications occurs on Facebook pages of RTP3, SIC Notícias, and TVI24, the participation is higher at the end of the night $(10 \mathrm{pm}-1 \mathrm{am})$. These results show that user 
participation is constant, which may corroborate with some studies that indicate that users access to SNS's several times a day (ERC, 2015; Newman et al., 2015; Oeldorf-Hirsch \& Sundar, 2015).

Despite the limitations identified on this paper, specifically in terms of the period of data collected (one week), in the future it is expected to increase the analysis period and to extend it to include other TV news channels.

In conclusion, the results suggest that the audience does not passively consume news content provided by news organizations, and increasingly uses SNS's to comment, share, and even create news content (Jenkins, 2006; Purcell et al., 2010).

\section{ACKNOWLEDGEMENTS}

The Instituto Politécnico de Viseu, the Center for Studies in Education, Technologies and Health (CI\&DETS) and the Portuguese Foundation for Science and Technology (FCT).

\section{REFERENCE LIST}

Aitamurto, T., \& Lewis, S. C. (2013). Open innovation in digital journalism: Examining the impact of Open APIs at four news organizations. New Media \& Society, 15(2), 314-331.

Alexa. (2016). Top Sites in Portugal. Retrieved 22th March, 2016, from http://www.alexa.com/topsites/countries/PT

Baresch, B., Knight, L., Harp, D., \& Yaschur, C. (2011). Friends who choose your news: An analysis of content links on Facebook. Paper presented at the ISOJ: The Official Research Journal of International Symposium on Online Journalism, Austin, TX.

Brandão, N. (2009). As Categorias Temáticas das Notícias dos Telejornais de Horário Nobre Portugueses. Paper presented at the $6^{\circ}$ Congresso SOPCOM, Lisboa.

Bruns, A., Highfield, T., \& Lind, R. A. (2012). Blogs, Twitter, and breaking news: The produsage of citizen journalism. Produsing theory in a digital world: The intersection of audiences and production in contemporary theory, 80(2012), 15-32.

Canelas, C. (2011). Os Efeitos da Convergência nos Media Noticiosos. Paper presented at the Congresso Nacional "Literacia, Media e Cidadania", Braga.

Castillo, C., El-Haddad, M., Pfeffer, J., \& Stempeck, M. (2014). Characterizing the life cycle of online news stories using social media reactions. Paper presented at the Proceedings of the 17th ACM conference on Computer supported cooperative work \& social computing.

Cazajeira, P. E. (2015). A audiência ubíqua do telejornalismo nas redes sociais $A$ Televisão Ubíqua (pp. 312). Covilhã: Livros LabCom.

Dias, S. S. (2010). Web TV - Análise e Melhores Práticas em OCS Nacionais e Internacionais. (Masters Degree), Universidade Nova de Lisboa.

ERC. (2015). Públicos e Consumos de Média: O consumo de notícias e as plataformas digitais em portugal e em mais dez países (pp. 116). Lisboa: Entidade Reguladora para a Comunicação Social.

Hermida, A., Fletcher, F., Korell, D., \& Logan, D. (2012). Share, like, recommend: Decoding the social media news consumer. Journalism Studies, 13(5-6), 815-824.

Hille, S., \& Bakker, P. (2014). Engaging the Social News User: Comments on News Sites and Facebook. Journalism Practice, 8(5), 563-572.

Jacobson, S. (2013). Does audience participation on Facebook influence the news agenda? A case study of the Rachel Maddow Show. Journal of Broadcasting \& Electronic Media, 57(3), 338-355.

Jenkins, H. (2006). Convergence Culture: Where Old and New Media Collide. New York: New York University Press.

Ju, A., Jeong, S. H., \& Chyi, H. I. (2014). Will social media save newspapers? Examining the effectiveness of Facebook and Twitter as news platforms. Journalism Practice, 8(1), 1-17. 
Lamas, S. (2013). A Formatação de Conteúdos Noticiosos para as Plataformas Broadcast e Online. (Masters), Universidade Nova de Lisboa, Faculdade de Ciências Sociais e Humanas.

Lopes, F. (1999). O Telejornal e o Serviço Público. Coimbra: Minerva Editora.

López, X. (2007). Gestión de las vías de participación en el ciberperiodismo. Estudios sobre el Mensaje Periodístico, 13, 11.

Mota, A., \& Barbosa, F. (2014). O Twitter e o Jornalismo. PRISMA.COM, 24, 48.

Newman, N., Levy, D. A., \& Nielsen, R. K. (2015). Reuters Institute Digital News Report 2015. Available at SSRN 2619576.

Oeldorf-Hirsch, A., \& Sundar, S. S. (2015). Posting, commenting, and tagging: Effects of sharing news stories on Facebook. Computers in Human Behavior, 44, 240-249.

Purcell, K., Rainie, L., Mitchell, A., Rosenstiel, T., \& Olmstead, K. (2010). Understanding the participatory news consumer. Pew Internet and American Life Project, 1, $19-21$.

Sousa, M. (2014). A Dinâmica da notícia nas redes sociais na internet - A circulação a partir do conteúdo das postagens no twitter e no facebook. contemporanea | comunicação e cultura, 12(2), 448-447. 